\title{
DESENVOLVIMENTO DA VAGEM DE FEIJÃO-CAUPI SOB INTERFERÊNCIA DE PLANTAS DANINHAS
}

\section{Carlos Zacarias Joaquim Júnior' ; Marcia Joaquim da Silva²; Nelito Nhanca N'Bali³; Inácio João Barbosa ${ }^{4}$; Lamine Sanó ${ }^{5}$ Luís Gustavo Chaves da Silva ${ }^{6}$}

${ }^{1}$ Engenheiro Agrônomo, Unesp, Jaboticabal, São Paulo, ${ }^{2}$ Engenheira Agrônoma, Unilab, Redenção, Ceará, ${ }^{3}$ Engenheiro Agrônomo, Udesc, Lages, Santa Catarina, ${ }^{4}$ Engenheiro Agrônomo, Unesp, Jaboticabal, São Paulo, ${ }^{5}$ Engenheiro Agrônomo, Udesc, Lages, Santa Catarina, ${ }^{6}$ Engenheiro Agrônomo, Unilab, Redenção, Ceará.

\section{DOI: 10.47094/ICONNECA.2021/3}

\begin{abstract}
RESUMO
Um dos maiores problemas encontrados na produção de feijão-caupi são as plantas daninhas, devido a competição e interferência causada por estas plantas. $O$ estudo visa avaliar o desenvolvimento das vagens de feijão-caupi submetidos ao convívio e controle de plantas daninhas. O estudo foi realizado em delineamento de blocos casualizados, com dez tratamentos e quatro repetições. Foram avaliados o comprimento da vagem, número de grãos por vagem e massa seca da vagem. Para as variáveis avaliadas, houve um decréscimo nos valores à medida que a cultura convive com as plantas daninhas e um acréscimo quando estas forem controladas, mantendo a cultura livre de competição. Sendo assim os valores máximos e mínimos encontrados são 18,1-16,2 cm; 13,8-10,8 e 75,28-73,54 gramas respectivamente.
\end{abstract}

PALAVRAS-CHAVE: Vigna unguiculata. Períodos de convivência. Matocompetição. ÁREA TEMÁTICA: Outros.

\section{INTRODUÇÃO}

O feijão-caupi (Vigna unguiculata (L.) Walp., também conhecido como feijão macassar, é uma das leguminosas com maior importância econômica para algumas regiões do Brasil, constituindose como uma das mais importantes fontes proteicas na alimentação da população rural (BEZERRA, et al., 2014). Devido os valores nutricionais desta cultura, ela vem contribuindo na nutrição humana para alguns países da África Ocidental (ADDY, et al., 2020).

O Brasil situa-se nos países com maior produção e consumo de feijão-caupi, uma vez a produtividade média do país em grãos está em torno de $525 \mathrm{~kg}_{\text {ha- }}{ }^{-}$e produção de 687,4 mil toneladas (CONAB, 2021). 
Um dos fatores que limitam o rendimento da cultura é a interferência causada pela comunidade infestante em áreas de cultivo, isso culmina também com a baixa produção, por razões da competição que se estabelece ao longo do crescimento e desenvolvimento da cultura (LACERDA, et al., 2020).

O objetivo deste trabalho é de avaliar o desenvolvimento das vagens de feijão-caupi submetidos ao convívio e controle de plantas daninhas.

\section{MATERIAL E MÉTODOS}

O experimento foi realizado em 2019 na área experimental do Campus das Auroras - Unilab, Redenção-CE, em delineamento de blocos casualizados, com dez tratamentos e quatro repetições. Os tratamentos foram divididos em duas parcelas (parcela subdividida), constituídos de períodos de controle (no limpo) ou convivência (no mato) das plantas daninhas com a cultura.

Os períodos de controle em DAE (dias após a emergência) foram em intervalos de 20 dias, sendo dessa forma: $0 \mathrm{DAE}$; 0 à $20 \mathrm{DAE}$; 0 à $40 \mathrm{DAE}$; 0 à $60 \mathrm{DAE}$; 0 à $80 \mathrm{DAE}$ que corresponde ao período de colheita. Foi utilizada a variedade crioula, que possui um ciclo de 71-90 dias, sendo considerado médio-precoce, de acordo com (EMBRAPA, 2002), provenientes do Sítio Nova Assunção de Aracoiaba-CE. O espaçamento foi de 0,50 entre fileiras e 0,25 entre plantas.

Em cada cova de $4 \mathrm{~cm}$ de profundidade, foram colocadas 4 sementes. A densidade foi de 16 plantas por cada parcela. $\mathrm{O}$ desbaste foi realizado 15 dias após a semeadura. A irrigação é feita com regadores manuais em dois períodos diários (manhã e tarde), em uma lâmina de 42 L diário, por cada parcela.

Após colheita, foram realizadas as avaliações do comprimento da vagem, número de grãos por vagem e massa seca da vagem de acordo com a metodologia de Lima (2015). Os dados foram submetidos a análise de regressão linear por grupos de tratamentos.

\section{RESULTADOS E DISCUSSÃO}

Para o comprimento da vagem, a média máxima atingida nos tratamentos de controle foi de $18,1 \mathrm{~cm}$ e de 16,2 cm para tratamentos em convívio. Sendo que, para os tratamentos de controle, apresentara uma diferença de 10,50\% em relação aos tratamentos de convívio, essa diferença pode afetar o número de grãos por vagem da cultura (gráfico 1). 
Gráfico 1: Comprimento da vagem em função dos períodos de controle (no limpo) e convivência (no mato) com as plantas daninhas. UNILAB, Redenção-CE, 2019.

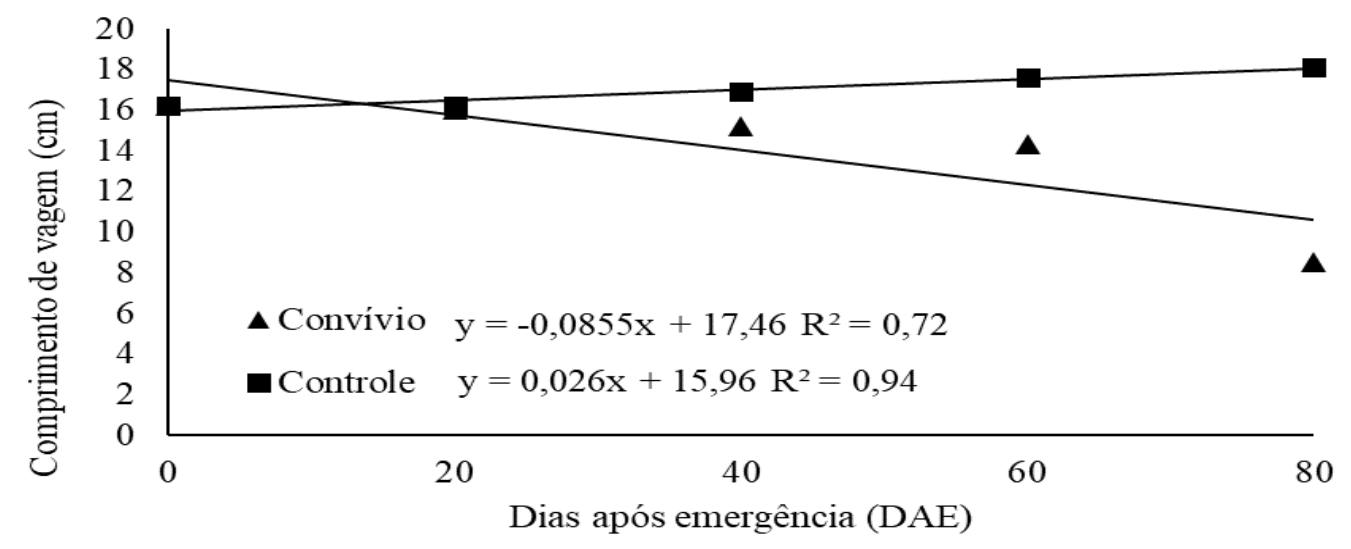

Fonte: Joaquim Jr., 2019

Os valores próximos são encontrados no trabalho de Santos (2014), analisando o desempenho agronômico de cultivar BRS Guariba e BRS Nova era, observou que o primeiro apresentou o máximo comprimento de vagem de $19,65 \mathrm{~cm}$ e o segundo de $16,35 \mathrm{~cm}$.

O número de grãos por vagem foi superior nos tratamentos de controle das plantas daninhas e inferior nos de convívio com a cultura. A média máxima atingida no controle foi de 13,8 grãos e 10,8 grãos para convívio. Para tratamentos de controle, houve uma diferença de $21,74 \%$ em relação aos tratamentos de convívio, essa diferença pode influenciar negativamente na produtividade da cultura (gráfico 2).

Gráfico 2: Número de grãos por vagem em função dos períodos de controle (no limpo) e convivência (no mato) com as plantas daninhas. UNILAB, Redenção-CE, 2019.

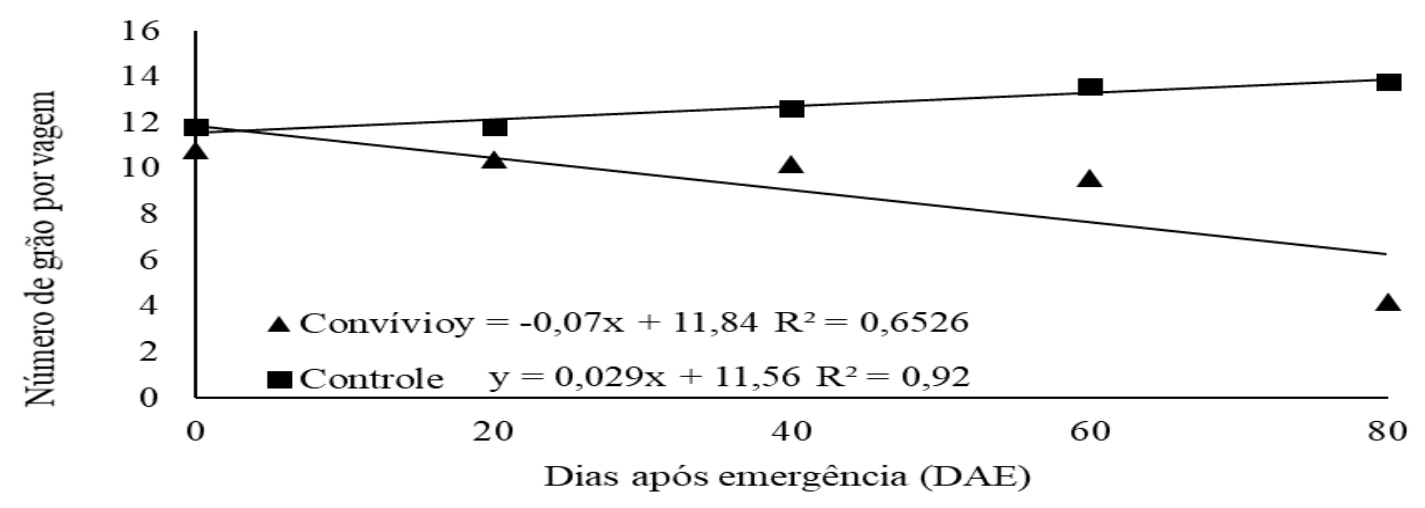

Fonte: Joaquim Jr., 2019 
Para a massa seca da vagem, a média máxima atingida nos tratamentos de controle foi de 75,28 gramas e de 73,54 gramas para tratamentos em convívio. Sendo que, para os tratamentos de controle, apresentara uma diferença de 2,32\% em relação aos tratamentos de convívio.

Gráfico 3: Massa seca da vagem em função dos períodos de controle (no limpo) e convivência (no mato) com as plantas daninhas. UNILAB, Redenção-CE, 2019.

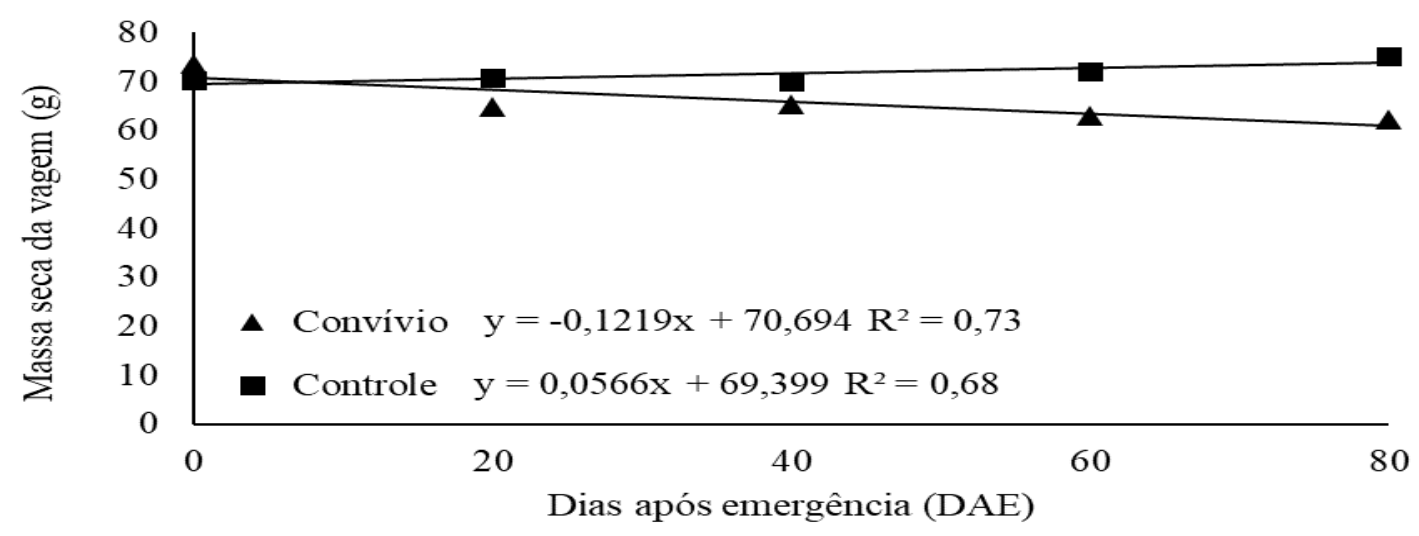

Fonte: Joaquim Jr., 2019

A oscilação das médias da massa seca, tanto nos períodos de convivência assim como nos de controle, deve-se a diferença no tamanho e na estrutura das vagens, provocada pela interferência de plantas daninhas.

\section{CONCLUSÃO}

A condução da cultura do feijão-caupi no convívio (mato) com as plantas daninhas, proporcionou a redução dos parâmetros avaliados da cultura em relação ao controle (limpo). Este fato se deve pela competição da cultura com a comunidade infestante durante o período crítico de competição, o que interfere diretamente na captura de recursos de sustento e produção, como: luz, nutrientes, água e gases, além da disputa pelo espaço e o conforto.

\section{PRINCIPAIS REFERÊNCIAS}

ADDY, S. N.T.T.; CICHY, K. A.; ADU-DAPAAH, H.; ASANTE, I. K.; EMMANUEL, A.; OFFEI, S. K. Genetic Studies on the Inheritance of Storage-Induced Cooking Time in Cowpeas [Vigna unguiculata (L.) Walp]. Frontiers in Plant Science, v. 11, n. 444, p. 1-9, 2020.

BEZERRA, M. A. F.; OLIVEIRA, F. A.; BEZERRA, F. T. C.; PEREIRA, W. E.; SILVA, S. A. Cultivo de Feijão-Caupi em Latossolos sob o Efeito Residual da Adubação Fosfatada. Revista Caatinga, 
v. 27, n. 1, p. 109-115, 2014.

CONAB - Companhia Nacional de Abastecimento. Boletim da Safra de Grãos: Quarto levantamento. 2021. Disponível: https://www.conab.gov.br/. Acesso: 20/04/2021.

EMBRAPA. Sistemas de produção: Cultivo de feijão-caupi (Vigna unguiculata (L.) Walp.). ISSN 1678-0256. Teresina-PI. Dezembro, 2002.

LACERDA, M. L.; ASPIAZÚ, I.; CARVALHO, A. J.; SILVA, A. F.; FERREIRA, E. A.; SOUZA, A. A.; CAMPOS, M. L.; BRITO, C. F. B. Periods of Weed Interference in Cowpea Crop in the SemiArid of Minas Gerais, Brazil. Revista Brasileirade Ciencias Agrarias, v. 15, n. 6749, p. 1-6, 2020.

LIMA, R. S. Levantamento fitossociológico de plantas daninhas na cultura do feijão-caupi (Vigna unguiculata (L.) Walp.) no Município de Vitória da Conquista-Ba. UESB, 2015. (Dissertação - Mestrado em Agronomia, Área de Concentração em Fitotecnia). 